\title{
Prediction of Achievement based on Different Dimensions of E-learning Materials in University of Mysore, India
}

\author{
Razieh Rahmani, ${ }^{1, *}$ and G. Sheela ${ }^{2}$ \\ ${ }^{1}$ Research Scholar, Department of Education, University of Mysore, India \\ ${ }^{2}$ Department of Education, University of Mysore, India \\ "Corresponding author: Razieh Rahmani, Research Scholar, Department of Education, University of Mysore, India. Tel: +98-9124845755, E-mail: razirahmani@gmail.com
}

Received 2017 March 09; Revised 2017 April 17; Accepted 2017 May 30.

\begin{abstract}
Background: Educational systems have adopted e-learning in high quantity all over the world and they are currently concerned about the quality of instruction. Different factors including pedagogical factors, technical factors, content issues, ease of use of elearning systems, and computer knowledge of the users constitute the quality dimensions. The present study examines the degree of which each dimension affects the achievement in e-learning settings.

Methods: The present semi-experimental research was conducted in teacher education colleges affiliated to University of Mysore, India, in 2015 - 2016. Pretest on educational psychology (EP) was administered to 72 students selected through purposive sampling technique. The students were treated through e-learning by the researcher for 16 sessions. EP posttest and E-learning dimensions evaluation questionnaire (ELDEQ) were administered at the end of the intervention. ELDEQ contained 58 questions on the quality of e-learning dimensions and it was constructed based on the evidence from content analysis. Face validity and content validity of the instrument were established through 13 experts in the field of e-content. Confirmatory Factor Analysis (CFA) was adopted to establish construct validity. Cronbach's alpha above 0.7 indicated the reasonable reliability of the instrument. SPSS 22 and multiple regression were utilized to analyze the data.

Results: The results indicated a difference between the effects of various dimensions including content dimension $(\mathrm{P}=0.001)$, technical dimension $(P=0.03)$, pedagogical dimension $(P=0.02)$, computer knowledge of the users $(P=0.47)$, and ease of use of elearning systems $(\mathrm{P}=0.17)$ on achievement.

Conclusions: Based on the results of the study, content dimension is the first and foremost predictor of learning. Pedagogical and technical dimensions were found to be the second and the third significant predictors of achievement, respectively.
\end{abstract}

Keywords: E-Learning Quality, Dimensions of E-Learning Quality, Content Quality of E-Learning, Technical Quality of E-Learning

\section{Background}

Advances in information technology as well as social changes have given rise to new patterns for education. These dramatic and extensive changes have had a considerable impact on systems of education and training (1). Elearning is the use of electronic technology to deliver, support, and improve learning and teaching.

The definition that most educationalists agree on is that e-learning is a set of synchronous and asynchronous instruction delivered to learners over technology with no restrictions on time and space $(2,3)$. Unlike high expenses of these facilities at the beginning, it saves lots of money and much less manual energy over time.

Quality of all dimensions of e-learning is an important factor influencing learning (4). It relates to obtaining the best learning achievement or excellence in performance (5).

Various dimensions of e-learning quality are as follows:

1) Technical quality, which refers to those characteris- tics of e-learning material that pertain primarily to the engineering principles involved in its development. The technical quality includes Metadata (6), effective multimedia (7), flexibility, appealing appearance (8), and Interoperability.

2) Content quality is a term that describes the quality of the information presented in e-learning. It is often pragmatically defined as "the fitness for use of the information provided." Content quality includes the following factors: Understandability (9), Appropriate level of information (10), Accuracy and veracity (11), Up-to-date (11), and Free of Bias (9).

3) Pedagogical quality is used to refer the quality of teaching and learning activities using technology-based resources. It relates to contexts in the school sector, where teachers normally direct the learner and to those contexts where the learners have a stronger role in managing the learning process. The followings are pedagogical factors in e-learning resources (12): learning objective (13), interaction and engagement (14), assessment, reusability (15), 
granularity (16), efficiency (10), Learning- oriented (16), motivating, and instructional design (13).

4) Ease of use of E-Learning system is about how userfriendly a chunk of content is. It refers to ease of navigation, predictability of the user interface, quality of the interface, and help features of the content (17). Ease of use of E-learning system includes the following factors: interface (8), readability of text (18), feeling of control, guide for use (19), and IT infrastructure.

5) Computer knowledge of user makes individuals able to use computers and related technologies and consequently enable them to use the e-content. Computer literacy level covers a wide range of skills (from basic to advance) as well as the level of comfort the users have when using it.

During the 60s and 70s, the world saw a growing interest in the use of computer in education. This was naturally followed by an interest in knowing the impact of digital resources on learning and the influences of technology on education. Extensive research has been conducted all over the world to examine the influence of digital resources on learning. The results of these studies, confirmatory and/or contradictory, seem to agree that the learning process accelerates and stimulates the way the subject matter is presented via a medium rather than the type of medium or the medium itself (20). Research has been conducted on technological infrastructure, hardware, and instructional material for several decades.

Jung in a survey of 795 adult learners to identify the quality dimensions of e-learning in South Korea confirmed interaction, staff support, institutional quality assurance mechanism, institutional credibility, learner support, information and publicity and learning tasks as seven dimensions in evaluating e-learning quality (21). The Swedish national agency for higher education (2008) suggested a 10-dimension model for the assessment of e-learning quality that includes content/material, communication, cooperation and interactivity, student assessment, structure/virtual environment, flexibility and adaptability, support (for teacher and students), staff qualifications and experience, institutional leadership, resource allocation, and the holistic and process aspect (22).

Frydenberg, in the meantime, extracted nine quality dimensions: institutional commitment; technology; student services; evaluation; course design and development; instructors; delivery; finances; regulatory and legal compliance (23).

McNaught identified the criterion in seven areas to be essential for ensuring quality of online education. It included clear planning; robust and reliable infrastructure; good support systems for staff and students, included training and written information; good channels of com- munication between staff and students; regular feedback to students on their learning; clear standards for courseware development; and ongoing evaluation with a strong student input (24).

Sun et al. conducted a survey to investigate the critical factors affecting learners' satisfaction in e-learning. The results of their study revealed that learner computer anxiety, instructor attitude toward e-learning, e-learning course flexibility, e-learning course quality, perceived usefulness, perceived ease of use, and diversity in assessments are the critical factors affecting learners' perceived satisfaction (25).

Howard-Rose and Harrigan tested the MERLOT model among 197 students from 10 different universities. MERLOT evaluation model focused on quality of content, potential effectiveness as a teaching-learning tool, and ease of use. The results were descriptive and did not distinguish the relative impact of individual model components (26).

Accordingly, the current study was undertaken to find any statistically significant difference in the influence of the different dimensions of e-learning on EP achievement.

In pursuance of the above objective of the study, the following hypothesis was formulated:

There is no statistically significant difference in the possible impact of the different dimensions of e-learning on EP achievement.

\section{Methods}

One-group pretest posttest experimental design was adopted to find out the possible impact of different dimensions of e-learning on achievement in EP. 72 B.Ed students from colleges affiliated to Mysore University, India, were selected through purposive sampling technique according to the following criteria:1) Number of the students (the colleges had more than 30 students in English medium) and 2) Administrative cooperation during academic year 20152016.

Since there were no tools available to evaluate the quality of e-learning system from students' point of view, E-learning dimensions evaluation questionnaire (ELDEQ) was constructed to evaluate e-learning quality. The items for the questionnaire were extracted from related texts through content analysis, and then each item was transformed into a question. The draft questionnaire was constructed in two parts: Part A that included demographic information (gender, age, and major) and Part B that included 81 questions referring to the quality of e-learning system including technical (metadata, effective multimedia, flexibility, appealing appearance and interoperability), content (accuracy, up to date, comprehendible, and 
free of bios), pedagogical (learning objective and assessment) dimensions, ease of use, and computer knowledge of user. Each question was followed by a five-point scale ranging from 1 to 5 (low to high). In order to establish face and content validity, the draft ELDEQ was discussed with 13 experts in the field of e-learning. Modifications were made to improve the language, remove ambiguity, and make the items comprehendible to the students. This resulted in deletion of 23 items and therefore, 58 items retained in the final questionnaire. The students were asked to grade the e-learning system dimension quality. Content validity index of 0.81 showed acceptable level of content validity and CFA was adopted to establish construct validity. Non-significant Chi-Square with p-value of 0.119 indicated that the empirical correlation matrix did not differ significantly from the fitted covariance matrix. Ideally, the chi-square statistic's p-value should be greater than 0.05 . Then, the chi-square was divided by degree of freedom to give Chi/df that was found to be 0.919 ; the value below 3 implied goodness of fit. Ideally, the chi-square divided by degree of freedom has to be as small as possible. Root mean square error of approximation (RMSEA) value was obtained as 0.023; since the value is less than 0.05, it shows low difference between the fitted covariance matrix and the empirical data-matrix, indicating the close fit of the model.

To determine the reliability of the ELDEQ, Cronbach's alpha method was employed. $\alpha$ was applied separately for five subscales of the questionnaire.

As Table 1 reports, Cronbach's alpha, which was found to be greater than 0.7 in all the five subscales of the questionnaire, indicates reasonable trustworthiness of all the subscales. Hence, the ELDEQ was found to possess high reliability.

\begin{tabular}{|lcc}
\hline Table 1. Reliability of ELDEQ & & \\
\hline Subscale & Number of Items & $\mathbf{a}$ \\
\hline Technical dimension & 12 & 0.8 \\
\hline Content dimension & 10 & 0.8 \\
\hline Pedagogical dimension & 23 & 0.91 \\
\hline Ease of use & 8 & 0.76 \\
\hline Computer knowledge of user & 3 & 0.71 \\
\hline
\end{tabular}

Pretest on EP achievement was administered to the students. Then, they were taught the selected units in EP by the researcher in 16 sessions spread over a period of three months through e-resources. Before the experiment, an online group (i.e., EP online group) was created in social network. The students were asked to join the online group and were given an opportunity to share their ideas and discuss about issues related to the topic. The students could also download materials uploaded on the page; they could interact with the teacher and other students. Finally, posttests on EP achievement and ELDEQ were administered to the participants. To avoid pretest sensitization, two parallel achievement tests were constructed as pretest and posttest in EP. Finally, multiple regression in SPSS software was applied to analyze the data. In order to consider ethical guidelines, the study was held on typical classroom practices and the participants were informed that they are participating in the study. They were free to accept or turn down the invitation to cooperate in research. During the research, the participants were not asked to write their names in the questionnaire because of the possibility of confidential information becoming known to others. Finally, at the end of the research, the subjects were thanked with a small gift.

\section{Results}

Enthusiasm growing in the use of e-learning and interest in knowing the impact of its different dimensions on achievement were fundamental concerns of the present research study. Table 2 presents the distribution of the sample by gender, age, major, and computer knowledge level.

Table 2. Distribution of Sample by Gender, Age, Subject, and Computer Knowledge Level

\begin{tabular}{l|c|c}
\hline \multirow{4}{*}{ Gender } & & Frequency \\
\hline \multirow{4}{*}{ Age } & Male & 31 \\
\cline { 2 - 3 } & Female & 41 \\
\cline { 2 - 3 } & $20-24$ & 40 \\
\cline { 2 - 3 } & $25-29$ & 11 \\
\cline { 2 - 3 } & $30-34$ & 10 \\
\hline \multirow{4}{*}{ Major } & $\geq 35$ & 11 \\
\cline { 2 - 3 } & Biology and Chemistry & 10 \\
\cline { 2 - 3 } & History and Language & 28 \\
\cline { 2 - 3 } & Geography & 11 \\
\cline { 2 - 3 } & Math and physics & 23 \\
\hline \multirow{4}{*}{ Computer knowledge } & Poor & 4 \\
\cline { 2 - 3 } & Moderate & 50 \\
\cline { 2 - 3 } & Good & 13 \\
\cline { 2 - 3 } & Very good & 5 \\
\hline
\end{tabular}

Ho: There is no statistically significant difference in the possible impact of the different dimensions of e-learning on EP achievement. 
In order to test the above null-hypothesis, it was necessary to compare the effect size of five dimensions of elearning. Hence, stepwise multiple regression with five predictors was adopted. SPSS output includes several tables, which will be explained in the following.

Table 3 presents correlation matrix that shows values of Pearson's correlation coefficients between every paired predictors along with the significance level. It is found that the achievement has a large positive correlation with content dimension $(\mathrm{r}=0.722, \mathrm{P}<0.001)$ whereas it has the least positive correlation with computer knowledge $(\mathrm{r}=0.109$, $\mathrm{P}=0.18$ ). Among all the predictors, content dimension was found to have the highest correlation with achievement $(r=0.722)$ while pedagogical dimension was found to have the second highest correlation $(r=0.594)$ and technical dimension was found to have the third highest correlation $(r=0.456)$. Technical dimension, content dimension, pedagogical dimension, ease of use, and computer knowledge were predictors of achievement as dependent variable. R-value of 0.791 indicates the multiple correlation coefficients between the e-learning dimensions as predictors of achievement. The value of R square shows that $62.6 \%$ of the variance of achievement is accounted by e-learning dimensions. Hence, it is concluded that the e-learning dimensions can explain a large amount of variation (62.6\%) for achievement. The rest (37.4\%) would be accounted by predictors other than the e-learning dimensions.

Table 4 shows the amount of contribution of the e-learning dimensions as individual predictors of EP achievement.

Table 4 reveals that the pedagogical dimension significantly predicts achievement (beta $=0.22, \mathrm{P}<0.05$ ).

Content dimension (beta $=0.52, \mathrm{P}<0.001$ ) and technical dimension (beta $=0.18, \mathrm{P}<0.05$ ) likewise significantly predict achievement. On the other hand, computer knowledge of user and ease of use of e-learning system could not predict achievement. The obtained Constant Bo value is 20.19, which means that the amount of achievement without contribution of predictors is 20.19. P value less than 0.05 in pedagogical, content, and technical dimensions reflects the genuine effect of these variables on achievement. Accordingly, content dimension has the highest contribution to achievement prediction. Equation 1 is developed by replacing the amount of coefficient in regression equation to predict achievement in EP based on the e-learning dimensions.

Equation to calculate achievement $=20.19+\left(3.13^{*}\right.$ pedagogical dimension $)+\left(8.17^{*}\right.$ content dimension $)+\left(3.19^{*}\right.$ technical dimension $)+\left(2.54^{*}\right.$ ease of use $)-\left(0.90^{*}\right.$ computer knowledge of user)

According to the equation, each predictor has its own coefficient and achievement is predicted from a combina- tion of all the predictors multiplied by their respective coefficient plus a residual. Residual or error is the difference between predicted value and observed value.

The findings of the study showed that the most important contribution to achievement prediction among the five dimensions of e-learning is related to the content dimension. Pedagogical dimension was found to be the second important predictor of achievement. The third important predictor of achievement was found to be the technical dimension. However, computer knowledge of the students and ease of use of e-learning system were not found to be significant predictors of achievement.

\section{Discussion and Conclusion}

Success of e-learning depends on something more than the teacher and the book. It relies on the quality of technology, pedagogy, and content as well as ease of use of e-learning system and computer knowledge of the user. Although some researches (Jung (21), Frydenberg (23), McNaught (24)) have extracted dimensions of elearning, there has been no research to prioritize the dimensions. The present research examined the amount of contribution of the mentioned factors to learning. The result showed the first and foremost priority is attributed to content property of e-learning. It suggests content should be accurate, up-to-date, and comprehendible. In each granule, an appropriate level of information should be presented. Text-intensive instructions must be avoided, especially on initial screens. Since e-learning has mass users, the content should be unbiased. Based on the findings, pedagogical property plays the second important role. This factor of e-learning includes learning objective and assessment. It should be able to motivate the learners and stir up their interest.

Technical property that includes metadata, effective multimedia, flexibility, appealing appearance, and interoperability stands third in priority of e-learning system. The result emphasises that e-learning's technical dimension should addresses the followings: (This finding is similar to the findings of the study by Mestre who had conducted a research to gauge design considerations for the design of e-learning material (27)).

- E-learning material should be tagged with information about it, which accordingly can help the user

- Principles of multimedia creation must be acknowledged. Graphics, voice, and animations must be used in preference to or in conjunction with the text.

- Sound should be available wherever necessary. Sound can be toggled on/off.

- If the content has been prepared using a font of a particular language, that particular font needs to be added to 
Table 3. Correlation Coefficient of E-Learning dimensions

\begin{tabular}{|c|c|c|c|c|c|c|c|}
\hline Variable & Achievement & $\begin{array}{c}\text { Technical } \\
\text { Dimension }\end{array}$ & $\begin{array}{c}\text { Content } \\
\text { Dimension }\end{array}$ & $\begin{array}{l}\text { Pedagogical } \\
\text { Dimension }\end{array}$ & Ease of Use & $\begin{array}{l}\text { Computer } \\
\text { Knowledge }\end{array}$ & \\
\hline \multirow{2}{*}{ Achievement } & Correlation & 1 & 0.45 & 0.72 & 0.59 & 0.28 & 0.1 \\
\hline & Sig & & $<0.001$ & $<0.001$ & $<0.001$ & $<0.001$ & 0.18 \\
\hline \multirow{2}{*}{$\begin{array}{l}\text { Technical } \\
\text { dimension }\end{array}$} & Correlation & 0.45 & 1 & 0.32 & 0.41 & 0.14 & 0.16 \\
\hline & Sig & $<0.001$ & & 0.003 & $<0.001$ & 0.1 & 0.08 \\
\hline \multirow{2}{*}{$\begin{array}{l}\text { Content } \\
\text { dimension }\end{array}$} & Correlation & 0.72 & 0.32 & 1 & 0.51 & 0.22 & 0.12 \\
\hline & Sig & $<0.001$ & 0.003 & & $<0.001$ & 0.03 & 0.15 \\
\hline \multirow{2}{*}{$\begin{array}{l}\text { Pedagogical } \\
\text { dimension }\end{array}$} & Correlation & 0.59 & 0.41 & 0.51 & 1 & 0.22 & 0.09 \\
\hline & Sig & $<0.001$ & $<0.001$ & $<0.001$ & & 0.02 & 0.2 \\
\hline \multirow{2}{*}{ Ease of use } & Correlation & 0.28 & 0.14 & 0.22 & 0.22 & 1 & 0.45 \\
\hline & Sig & $<0.001$ & 0.1 & 0.03 & .02 & & $<0.001$ \\
\hline \multirow{2}{*}{$\begin{array}{l}\text { Computer } \\
\text { knowledge }\end{array}$} & Correlation & 0.1 & 0.16 & 0.12 & 0.09 & 0.45 & 1 \\
\hline & Sig & 0.18 & 0.08 & 0.15 & 0.2 & $<0.001$ & \\
\hline
\end{tabular}

Table 4. Coefficient of Individual Contribution of E-Learning Dimensions to Prediction of Achievement

\begin{tabular}{|c|c|c|c|c|c|c|}
\hline Model & B & SE & Beta & T-Value & P Value & VIF \\
\hline Constant & 20.19 & 7.68 & & 2.62 & 0.01 & \\
\hline Pedagogical dimension & 3.13 & 1.32 & 0.22 & 2.36 & 0.02 & 2.55 \\
\hline Content dimension & 8.17 & 1.38 & 0.52 & 5.90 & $<0.001$ & 2.47 \\
\hline Technical dimension & 3.19 & 1.44 & 0.18 & 2.21 & 0.03 & 2.41 \\
\hline Computer knowledge & -0.9 & 1.24 & -0.06 & -0.72 & 0.47 & 1.01 \\
\hline Ease of use & 2.54 & 1.78 & 0.12 & 1.37 & 0.17 & 2.8 \\
\hline
\end{tabular}

the material to be interoperable. In general, learning material should be produced in a way that it could be run in different computer systems.

This research showed that two of the factors, i.e. computer knowledge of user and ease of use, were not statistically significant. E-learning was found equally effective in enhancing EP achievement among students possessing poor, moderate, good, and very good levels of computer knowledge. This finding is in contrast to the results of Robin (28), Siong-Hoe and Woods (29), and Conceicao and Lehman's research, which indicated that some of the students with low experience in use of computers were not able to use e-learning (30).

The results of this study provide insights for teachers, students, and e-learning stockholders to strengthen e-learning implementation. They should develop well design content rather than just equip their institution with high tech equipment. Finally, although the present research tried to incorporate dimensions of e-learning, there were some limitations. The study indicated the ef- fect of e-learning dimensions on achievement, while there are many other variables that might affect the teachinglearning process. Hence, the study suggests future researchers to incorporate more variables into their investigation.

\section{References}

1. Khan BH. Web-based training: Educational Technology. ;2001.

2. Harrison TM, Stephen T. Computer networking and scholarly communication in the twenty-first-century university. SUNY Press; 1996.

3. Leidner DE, Fuller M. Improving student learning of conceptual information: GSS supported collaborative learning vs. individual constructive learning. Decision Support Systems. 1997;20(2):149-63. doi: 10.1016/s0167-9236(97)00004-3.

4. Piccoli G, Ahmad R, Ives B. Web-Based Virtual Learning Environments: A Research Framework and a Preliminary Assessment of Effectiveness in Basic IT Skills Training. MIS Q. 2001;25(4):401. doi: 10.2307/3250989.

5. Ehlers UD. Quality in e-learning: use and dissemination of quality approaches in European e-learning: a study by the European Quality Observatory. Office for Official Publications of the European Communities; 2005. 
6. Balatsoukas P, Garoufallou E, Asderi S, Siatri R. A survey on the importance of learning object metadata for relevance judgment. Metadata Semantic Res. 2011:300-11.

7. Ling SW, Yuen MC, Chuah KM. Optimizing Multimedia Learning Objects for Learning in a Procedural-based Course. ; 2015.

8. Clark RC, Lyons C. Graphics for learning: Proven guidelines for planning, designing, and evaluating visuals in training materials. John Wiley \& Sons; 2010.

9. Chawla S, Gupta N, Singla RK. LOQES: model for evaluation of learning object. Int J Adv Comput Sci Appl. 2012;3(7):73-9.

10. Alla MMSO, Faryadi Q. The effect of information quality in e-learning system. Int J Appl. 2013;3(6).

11. Gibbons AS, Nelson J, Richards R. The nature and origin of instructional objects. The instructional use of learning objects. Bloomington. Association for Educational Communications and Technology; 2000.

12. Garrison DR. E-learning in the 21st century: A framework for research and practice. Taylor \& Francis; 2011.

13. Alonso F, Lopez G, Manrique D, Vines JM. Learning objects, learning objectives and learning design. Innov Educ Teach Int. 2008;45(4):389400. doi: $10.1080 / 14703290802377265$.

14. Bouhnik D, Marcus T. Interaction in distance-learning courses. J Am Soc Inf Sci Technol. 2006;57(3):299-305. doi:10.1002/asi.20277.

15. Brande S. Learning objects for instruction: Design and evaluation - By Pamela T Northrup. Br J Educ Technol. 2010;41(6):977-8. doi: 10.1111/j.1467-8535.2010.01135_1_8.x.

16. Polsani PR. Use and abuse of reusable learning objects. J Digital Inf. 2006;3(4).

17. Lau SH, Woods PC. An investigation of user perceptions and attitudes towards learning objects. Br J Educ Technol. 2008;39(4):685-99. doi: 10.1111/j.1467-8535.2007.00770.x.

18. Ozkan S, Koseler R. Multi-dimensional students' evaluation of e-learning systems in the higher education context: An empirical investigation. Comput Educ. 2009;53(4):1285-96. doi: 10.1016/j.compedu.2009.06.011.
19. Liaw SS, Huang HM, Chen GD. Surveying instructor and learner attitudes toward e-learning. Comput Educ. 2007;49(4):1066-80. doi 10.1016/j.compedu.2006.01.001.

20. Clark RC. Developing technical training: A structured approach for developing classroom and computer-based instructional materials. John Wiley \& Sons; 2011.

21. Jung I. The dimensions of e-learning quality: from the learner's perspective. Educ Technol Res Dev. 2010;59(4):445-64. doi: 10.1007/s11423 010-9171-4.

22. Hansson H. E-learning quality. Aspects and criteria for evaluation of e-learning in higher education. ; 2008.

23. Frydenberg J. Quality Standards in eLearning: A matrix of analysis. Int Rev Res Open Distrib Learn. 2002;3(2) doi: 10.19173/irrodl.v3i2.109.

24. McNaught C, editor. Quality assurance for online courses: From policy to process to improvement. Meeting at the Crossroads. 2001; pp. $435-42$

25. Sun PC, Tsai RJ, Finger G, Chen YY, Yeh D. What drives a successful e-Learning? An empirical investigation of the critical factors influencing learner satisfaction. Comput Educ. 2008;50(4):1183-202. doi: 10.1016/j.compedu.2006.11.007.

26. Howard-Rose D, Harrigan K. CLOE learning impact studies lite: Evaluating learning objects in nine Ontario university courses. Retrieved July. 2003;3:2007.

27. Mestre LS. Matching up learning styles with learning objects: What's effective? J Lib Administ. 2010;50(7-8):808-29.

28. Kay RH. Examining Factors That Influence the Effectiveness of Learning Objects in Mathematics Classrooms. Can J Sci Math Technol Educ. 2012;12(4):350-66. doi: 10.1080/14926156.2012.732189.

29. Lau SH, Woods PC. Understanding learner acceptance of learning objects: The roles of learning object characteristics and individua differences. Br J Educ Technol. 2009;40(6):1059-75. doi: 10.1111/j.14678535.2008.00893.x.

30. Lehman RM, Conceicao SCO. Creating a sense of presence in online teaching: How to" be there" for distance learners. 18. John Wiley \& Sons; 2010 